\title{
OBSERVAÇÄO IN VITRO DE Eurytrema coelomaticum EM MEIOS DE CULTIVOS 1
}

\author{
MILTON HISSASHI YAMAMURA 2 \\ ALINE ARTIOLI MACHADO YAMAMURA 2 \\ MICHAEL ROBIN HONER 3
}

\begin{abstract}
YAMAMURA, M.H.; YAMAMURA, A.A.M.; HORNER, M,R. Observaçāo in vitro de Eurylrema coelomaticum em meios de cultivos. Semina: Ci. Biol,/Saúde, Londrina, v. 13, n. 2, p. $58-60$, jun. 1992.

\section{RESUMO}

Para a manutenção de Eurytrema coelomaticum em condiçóes experimentais foram testados os meios de cuitura Gay ABC, 199 e soro de animais. O critério para observar a sobrevida deste trematódeo foi a motilidade através do auxhio de um microscopio estereoscópio. O melhor meio foi o soro ovino, sendo possível observar a sobrevivência por mais de 1200 horas e um do fatores para o prolongamento de tompo de sobrevivência foi o controle de microorganismos. Também foram registrados os dados de ovipostura média diária, que foi de 641 ovos, tendo como média as primeiras 24 horas (473) ovos e às 24 horas seguintes (673) ovos. A média diária de ovipostura foi considerada baixa e bastante irregular.
\end{abstract}

PALAVRAS-CHAVE: Eurytrema coelomaticum; Cultivo "in vitro"; Ovipostura "in vitro"

\section{1 - INTRODUÇẨO}

Um dos primeiros passos no estudo de fisiologia de um determinado parasito é a tentativa de mantê-lo vivo, fora da sua localizaçāo habitual nos hospedeiros por maior tempo, possibilitando assim, a verificaçāo dos efeitos anti-helmiticos "in vitro".

Estas tentativas foram realizadas por ROSS \& BUELDING (1950) que testaram soro bovino filtrado e nāo filtrado, e verificaram que o perfodo de sobrevivência de Schistosom mansoni näo diferiu nestes dois meios, indicando que o metabolismo respiratório tem pouca importância na manutençăo da espécie em condiçōes experimentais, mas em se tratando de Litomosoides carinii, os mesmos autores, observaram que a sobrevivência da espécie foi de 12 horas e de sete dias em condiçôes anaeróbica e aeróbica, respectivamente.

O presente trabalho teve como objetivo avaliar a sobrevivência de Eurytrema coelomaticum em meios de cultura, tais como Gay ABC, 199 e soro de ovino. A finalidade principal foi obter informaçōes a serem empregadas nos testes anti-helmínticos "in vitro", e também observar a ovoposição média deste trematódeo em condiçōes experimentais.

\section{2 - MATERIAL E MÉTOdOS}

Para a manutenção de Eurytrema em condiçōes experimentais foram utilizados soro de ovino e os meios de Gay $A B C$ e 199.

Os espécimes do trematódeo foram colhidos, em condiçōes assépticas, do ducto pancreático de bovinos naturalmente infectados.

Foram selecionados 10 parasitos de um total de 10 pâncreas parasitados, os quais foram acondicionados em recipiente de vidro com capacidade de $10 \mathrm{ml}$ e com tampa de borracha. Em cada recipiente foi colocado $1 \mathrm{ml}$ do meio de cultura e incubado em estufa a $38^{\circ} \mathrm{C}$.

O critério para observar a sobrevida dos trematódeos nos meios de cultivo foi através da motilidade do parasito. No caso de dúvidas, recorreu-se ao uso de microscópio estereoscópio, principalmente após longo período de manutençāo nos meios, quando o parasito perde muito a motilidade.

Baseando-se nas técnicas utilizadas no cultivo do Eurytrema "in vitro" foi observada ovoposição média diária deste parasito. A cada 24 horas foi renovado o meio de cultura. A contagem dos ovos foi efetuada a cada 24 horas e foram consideradas somente as amostras que

1 - Projeto financiado pelo CNPq

2 - Departamento de Medicina Veterinária Preventiva - CCAJUniversidade Estadual de Londrina, Caixa Postal 6001, CEP 86051-970, Londrina - Paraná - Brasil

3 - Embrapa - Campo Grande/MS 
sobreviveram mais de 48 horas, possibilitando assim duas leituras consecutivas em um espaço de 24 horas cada uma.

\section{3 - RESULTADOS E disCUSSÃo}

\section{1 - Cultivo in vitro de forma aduita}

Os meios de cultivo náo mostraram ser adequados a manutenção de Eurytrema, pois os parasitos morreram em um período inferior a 24 horas, talvez devido a mudança do $\mathrm{pH}$, verificada pela alteraçăo de cor do meio de cultura, que possui indicador de $\mathrm{pH}$ em sua composição.

MICHALS \& PRATA (1968), utilizaram o meio 199 para o cultivo de S. mansoni, porém acrescido de soro em uma proporção de 9 para 1.

A sobrevivencia de E. coelomaticum, em soro de ovino, por um maior período de tempo, foi possível, quando o parasito era mantido no mesmo frasco, sem efetuar a troca do meio. Quando se fez a troca, a cada 72 horas, a contaminação nāo permitiu a sobrevivência do parasita neste meio. Isto evidencia que, um dos fatores que prolongou a sobrevivencia do parasito em soro foi o controle de microorganismos. Este fato também foi observado por STEPHENSON (1947) quando trabalhou com a manutenção "in vitro" de F. hepalica, que teve uma sobrevida de 75 horas. Um dos elementos que compunham 0 meio, era o boråx, sabidamente um agente bacteriostático.

ROHBACHER (1957), confirmou também, que a ausência de bactérias foi essencial na manutençāo "in vitro" de $F$. hepatica. O trematódeo viveu em excelentes condiçōes por três a quatro semanas.

SAKAMOTO et al (1984), ressaltaram a dificuldade na obtençāo de trematódeos em condições assépticas de pâncreas de bovinos abatidos em matadouros. Propuseram entāo, efetuar os estudos "in vitro" de forma asséptica, a partir de cercárias, colhidas de esporocistos, que eram expelidos pelo caramujo terrestre.

$O$ desenvolvimento de $E$. coolomaticum foi obtido em condiçōes aeróbicas e os resultados podem ser vistos na Figura 1. A sobrevivência da metade da populaçäo ocorreu ao redor de 96 horas, $20 \%$ sobreviveram por 216 horas, $10 \%$ por 504 horas, $3 \%$ por 1032 horas e $1 \%$ por mais de 1200 horas.

Os trematódeos pancreáticos, mantidos em soro ovino, perderam o brilho e a sua cor vermelha, tornando-se opacos, porém mantiveram a ovipostura.

Muitos autores consideram o soro animal como um meio que prolonga a vida de parasitos em condiçōes experimentais, entre eles BERETTA \& LOCATELLI (1968). Os mesmos verificaram que espécimes de Fasciola hepatica, quando mantidos em meio de Tyrode, acrescido de soro bovino na proporção de $1: 1$, começaram a morrer após 36 horas, enquanto que em meio simples de Tyrode, estes morriam a partir de 24 horas. Metade da amostra morria em 60 horas e em meio acrescido de soro este tempo era de 120 horas. Concluiram os autores que, 0 soro bovino representa um fator de sobrevida para
F. hepatica em condiçōes experimentais.

Quanto as exigências nutricionais de E. coelomaticum, estas sāo obtidas nos canais pancreáticos e também no figado. Quando este se localiza nos ductos biliares de ovino, o seu tamanho nāo difere daquele encontrado no pâncreas, significando que o E. coelomaticum pode encontrar elementos essenciais ao seu desenvolvimento também nos ductos biliares.

No presente trabalho o soro não sofreu nenhum tratamento, este procedimento foi utilizado para obter conhecimento prévio sobre o emprego do soro animal como substrato nos testes "in vitro" de drogas anti-helminticas.

ROSS \& BUEDING (1950), demonstraram que as proteínas e outros componentes näo dialisáveis do soro tinham pouca importância na sobrevivência de um organismo de matabolismo respiratório facultativo como S. mansoni.

\section{2 - Observaçāo sobre ovipostura}

Nos resultados obtidos de oito amostras e com 47 contagens, a média diária de ovipostura foi de 641 ovos, com variaçäo de 12 a 3434 ovos por parasito e a variação por amostra de 247 a 1272 . Considerando que um bovino de 500 kilogramas produz em media 41500 gramas de fezes diariamente, se exames coprológicos fossem realizados $_{x}$ estes números corresponderiam a $15 ; 0,2 ; 82 ; 6$ e 30 respectivamente, admitindo-se uma carga parasitária de 1000 trematódeos.

No presente trabalho foram considerados os resultados das primeiras 24 horas, com uma media de 473 e em 48 horas seguintes, uma média de 673 ovos. Em decorrência da troca diária do meio do recipiente, e mesmo mantendo assepsia, näo foi possivel considerar a leitura em 72 horas, porque os parasitos morriam devido a contaminação por bactérias.

Estes dados foram diferentes daqueles obtidos por LOCATELLI \& PAOLETTI (1969), que contaram 1800 ovos de $F$. hepatica nas primeiras 24 horas e 300 ovos em 48 horas, e entre 72 horas até 144 horas nāo ocorreu a postura. Demonstrando a dificuldade de adaptação deste trematódeo ao meio empregado neste experimento e a perda gradativa de motilidade, acarretando assim uma diminuição de ovipostura.

O número médio diário de ovos de E. coelomaticum foi considerado baixo e bastante irregular. Isto justifica a dificuldade em detectar ovos nas fezes de animais naturalmente infectados e portadores de pequeno número de parasitas no pâncreas.

\section{4 - CONCLUSŌES}

O soro de ovino constituiu-se em um meio ideal de cultivo "in vitro" de E. coelomaticum, sendo observada a sobrevivência por um período de 1200 horas;

A ovipostura média diária "in vitro" de E. coelomaticum foi de 641 ovos, embora bastante irregular.

Semina Ci. Biol./Saúde, Londrina, v, 13, n. 2, p. $58-60$, jun. 1992 
YAMAMURA, M.H.; YAMAMURA, A.A.M.; HORNER, M.R. Cultivation in vitro of Eurytrema coelomaticum. Semina:

Ci. BiolJSaúde, Londrina, v. 13, n. 2, p. $58-60$, june 1992.

\section{ABSTRACT}

Culture media Gay ABC, 199 and animal's serum have been used in "in vitro" cultivation of Eurytrema coelomaticum. The criterion for recording the survival was through the motility and the observation by means of a stereoscopic microscope. The best result was obtained by the use of sheep's serum, when it was observed that this trematode can be maintained alive for more than 1200 hours and one of the reasons for this was that all experiments were conducted under aseptic conditions. Data on the rate of egg laying by E. coelomaticum were observed. The average daily rate per worm was 641 eggs. In the first 24 hours, the average was 473 eggs and it increased in 48 hours to 673 eggs per day. The average daily rate of $E$. coelomaticum was considered low and extremely irregular.

KEY-WORDS: Eurytrema coelomaticum, "In vitro" cultivation; "In vitro" egg laying

\section{REFERÊNCIAS BIBLIOGRÁFICAS}

BERETTA, C. \& LOCATELLL, A. Effetl in vitro del 2-iodo ciano-6-nitrofenolo sulla Fasciola hepatica. Atb Della Societá delle Scienze Veterinanc, v. 22, p. 260-264, 1968.

LOCATELLI, A.; PAOLETTI, C. Caltivazione in vitro di Fasciola hepatica adulte: produzione di uova. Nota Preventiva. Atti dela Societí ftaliana delle Scienze Veterinarie, v. 23, p. 879-881, 1969.

MICHAEL, R.M.; PRATA, A. Evolution and characteristic of Schistosoma mansoni egg laid in vitro. \& Parasitol, v. 54, p. 921-930, 1968 .

ROHRBACHER, G.H. Observations on the survival in vitro ob bacteria iree adult common liver flukes Fasciola hepatica $\mathrm{L}$. 1758 J. Parasitol, v. 43, p. 9-18, 1957.
ROSS, D.A.; BUEDING, E. Survival of Schistosoma mansoni in vitro. Proc Soc Exp. Biol. Mod., v. 73, p. 179-182, 1950.

SAKAMOTO, T.; KONO, I.; MOHRI, S. Studles on Eurytrema coelo maticu $\mathrm{m}$. IV Comparasion between anthelmintic effects of drug against Eurytrema coelo matiou $m$ in vitro and in vivo. $J$. Fac. Agr. Iwate Univ., v. 17, n. 2, p. 211-222, 1984.

STEPHENSON, $W$. Phystological and histochemical observations on adult liver fluke Fasciola hepatica L. I Survival in vitro. Parasitology, v. 38, p. 116-122, 1947.

Recebido para publicą̧āo em 31/10/1991 